\title{
Effects of Monacolin K of Red Rice and Glucomannan, Combined with a Low Calorie Diet, in Treatment of Dyslipidemia and Hypertension
}

Teresa Esposito, Salvatore Allocca, Laura Adelfi, Giovanni Messina, Marcellino Monda* and Bruno Varriale

Department of Experimental Medicine, Second University of Naples, Naples, Italy

\begin{abstract}
Alarming increase in incidence of cardiovascular disease is result of a nutrition pattern characterized by an increase in consumption of fats, cholesterol, sugar and other refined carbohydrates, concomitant with low consumption of polyunsaturated fatty acids and fibers. The purpose of this study was to evaluate the efficacy of the monacolin $\mathrm{K}$ of red rice and glucomannan, associated with low-calorie diet, on improvement of lipid profile and hypertension, symptoms of metabolic syndrome. In 180 Neapolitan patients with metabolic syndrome, we evaluated effects of monacolin $\mathrm{K}$ of red rice and glucomannan, associated with a low-calorie diet, on total cholesterol (CT), LDL cholesterol (LDL), HDL cholesterol (HDL), triglycerides (TG) and blood pressure (BP). The results showed a significant decrease in average value of CT $(-20 \%)$, LDL $(-25 \%)$, TG $(-20 \%)$, with an increase in HDL $(+15 \%)$ and a decrease in BP $(-20 \%)$. These findings corroborate evidences showing a therapeutic effects of these nutraceuticals in the treatment of dyslipidemia and hypertension, when a low-calorie diet alone is ineffective.
\end{abstract}

Keywords: Hypertension; Dyslipidemia; Cholesterol; Blood

pressure

\section{Introduction}

Metabolic syndrome is a medical condition deserving of special attention because of its prevalence and impact [1]. This term does not indicate a single disease, but a group of predisposing factors which, joined together, place the subject in a band of high risk for diseases such as diabetes, cardiovascular problems and hepatic steatosis [2-5].

Numerous epidemiological and experimental studies have demonstrated that metabolic syndrome affects almost half of adults over 50-60 years [4,6-12]. Probably, this incidence will grow in the future, considering spreading childhood obesity. An excess of body fat, especially when it is localized in the abdominal region, leads to an imbalance of the metabolism of fats and sugars that induces hyperinsulinemia (high insulin level in the blood, an indicator of increased resistance to this hormone) $[9,13]$. In addition to strategies based on changing lifestyle, it is frequent utilization of natural substances, with beneficial properties [14-18]. Monacolin K of red rice (10 $\mathrm{mg}, 90 \%$ by policosanol) is able to inhibit the HMG-CoA reductase, which is a key enzyme in the biosynthesis of cholesterol. Glucomannan ( 3 g per day) is particularly useful in the reduction of body weight and cholesterol [19]. It is also useful in constipation to regulate bowel function alternately in irritable bowel syndrome. The use of these products called "nutraceuticals" would appear useful in patients with poor tolerance to traditional drugs or those who reject traditional drugs [20-23]. The purpose of the study was to evaluate efficacy of the monacolin $\mathrm{K}$ of red rice and glucomannan, associated with low-calorie diet, on improvement of lipid profile and hypertension, symptoms of metabolic syndrome.

\section{Materials and Methods}

180 subjects ( 83 females and 97 males) with mild to moderate hypercholesterolemia, (range of total cholesterol between 200 and 290 $\mathrm{mg} / \mathrm{dl}$ ), mild hypertension (no antihypertensive drug therapy; 140159/90-99 mm Hg systolic/diastolic blood pressure), in which low-fat diet for three months did not achieve the treatment goal, were treated also with monacolin $\mathrm{K}$ of red rice ( $10 \mathrm{mg}$, $90 \%$ in policosanol per day) and fiber glucomannan ( 3 g per day) for 24 weeks. Blood pressure (BP), lipid profile [total cholesterol (CT), LDL cholesterol (LDL), HDL cholesterol (HDL), triglycerides (TG)], biochemical parameters related to tolerability (GOT, GPT, CPK) and body mass index were determined at baseline (T0), to 12th week (T1) and 24th week (T2). All biochemical parameters were performed by a single laboratory accredited to ISO parameters accuracy. All subjects expressed informed consent. The data were expressed as mean \pm standard deviation $(\mathrm{M} \pm \mathrm{DS})$ and percentage (\%) values. Significance of differences between groups was determined by Student's test for paired data, for linear data and the X2 for nonparametric data (Table 1).

\section{Results}

The results are reported in table. Monacolin $\mathrm{K}$ of red rice and fiber glucomannan, associated with a low-calorie diet, for 24 weeks showed a reduction in CT, LDL and systolic-diastolic BP. At T1 COL was reduced by $12.8 \%$ in males and $13 \%$ females, LDL was reduced by $15 \%$ in males and $16.2 \%$ females. HDL was increased by $6.1 \%$ in males and $6.6 \%$ females, TG were reduced by $14.9 \%$ in males and $13 \%$ females. BP was decreased by $20 \%$ for both diastolic and systolic values. At T2 COL was reduced by $19.3 \%$ in males and $19.5 \%$ in females, LDL was reduced by $25.2 \%$ in males and $27 \%$ females; HDL was increased by $11.2 \%$ in males and $15.4 \%$ females. TG were reduced by $22 \%$ in males and $21 \%$ females. Body weight decreased in association to decrease in lipid parameters.

*Corresponding author: Marcellino Monda, Professor, Department of Experimental Medicine, Section of Human Physiology, and Clinical Dietetic Service, Second University of Naples, Via Costantinopoli 16, 80138 Naples, Italy, Tel: +39 +81566 5804; Fax: +39 +81 5665841; E-mail: marcellino.monda@unina2.it

Received July 27, 2015; Accepted September 05, 2015; Published September 12, 2015

Citation: Esposito T, Allocca S, Adelfi L, Messina G, Monda M, et al. (2015) Effects of Monacolin K of Red Rice and Glucomannan, Combined with a Low Calorie Diet in Treatment of Dyslipidemia and Hypertension. Biol Med (Aligarh) 7: 250. doi: 10.4172/0974-8369.1000250

Copyright: $\odot 2015$ Esposito T, et al. This is an open-access article distributed unde the terms of the Creative Commons Attribution License, which permits unrestricted use, distribution, and reproduction in any medium, provided the original author and source are credited. 
Citation: Esposito T, Allocca S, Adelfi L, Messina G, Monda M, et al. (2015) Effects of Monacolin K of Red Rice and Glucomannan, Combined with a Low Calorie Diet, in Treatment of Dyslipidemia and Hypertension. Biol Med (Aligarh) 7: 250. doi: 10.4172/0974-8369.1000250

Page 2 of 3

\begin{tabular}{|c|c|c|c|c|c|c|}
\hline & Basal & \multicolumn{2}{|c|}{ 12th week } & \multicolumn{2}{|c|}{ 24th week } & \multirow{2}{*}{$\begin{array}{c}\text { Statistical significance } \\
p \\
\end{array}$} \\
\hline & $M \pm D S$ & $M \pm D S$ & D \% vs Basale & $M \pm D S$ & D \% vs Basale & \\
\hline Total cholesterol (mg/dl) & $262 \pm 35$ & $228 \pm 32$ & -12.7 & $213 \pm 27$ & -19.5 & $\geq 0.01$ \\
\hline LDL cholesterol (mg/dl) & $179 \pm 29$ & $149 \pm 28$ & -15.6 & $135 \pm 24$ & -25.9 & $\geq 0.01$ \\
\hline HDL cholesterol (mg/dl) & $52 \pm 12$ & $54 \pm 14$ & 6.7 & $55 \pm 13$ & 13.4 & n.s \\
\hline Triglycerides (mg/dl) & $175 \pm 13$ & $135 \pm 46$ & -14 & $136 \pm 35$ & -20.2 & n.s \\
\hline Systolic blood pressure $(\mathrm{mmHg})$ & $150 \pm 9$ & $141 \pm 10$ & -9 & $117 \pm 5$ & -33 & $\geq 0.01$ \\
\hline Diastolic blood pressure $(\mathrm{mmHg})$ & $94 \pm 4$ & $87 \pm 5$ & -7 & $77 \pm 6$ & -17 & $\geq 0.01$ \\
\hline Body mass index & $28.1 \pm 2.2$ & $26.1 \pm 2.5$ & -6.4 & $24.9 \pm 2.3$ & $-11,3$ & $\geq 0.01$ \\
\hline
\end{tabular}

Table 1: Average values (SD) at baseline at 12 th week and 24 th week in 180 patients.

\section{Discussion}

High COL is one of many factors that predispose to cardiovascular diseases. Some of these factors are modifiable (smoking cigarette, blood pressure, diabetes mellitus), while others are called non-modifiable (age, sex, family history and genetic factors). The influence of diet on COL is on average equal to $15 \%$, although significant modifications of the contribution dietary can cause variations up to a $\pm 30 \%$. Possible failure of the diet requires use of lipid-lowering agents. Medicines used in presence of hypercholesterolemia are statins (HMG-CoA reductase) and fibrates (most useful in presence of high triglycerides).

An alternative strategy to classical pharmacological intervention is use of nutraceuticals with a good tolerability profile and activity on lipid profile [24]. A good effect on cholesterol synthesis is obtained by policosanol. These depress expression of HMG-CoA-reductase in concentration-dependent manner, probably by receptor-mediated mechanisms that inhibit transcription for this enzyme [25,26]. Some studies showed that policosanol induces other effects on cardiovascular risk, similar to pleiotropic effects attributed to statins [27]. Red rice to $5 \%$ in monacolin $\mathrm{K}$ is a natural substance that is used for thousands of years in China to achieve desirable values of cholesterol. Glucomannan is a polysaccharide with high molecular weight, is extracted from tuber of Amorphophallus konjac, a plant used in Japanese cuisine as an agent gelatificator. This fiber has the ability to attract a lot of water, increasing its volume up to 60-100 times and giving rise to a soft gelatinous mass. This feature gives glucomannan a dual effect: it reduces sense of hunger and absorption of fats and sugars, which are trapped in soft, viscous mass that forms in the intestine [27-34].

The present study showed that monacolin $\mathrm{K}$ of red rice and glucomannan is useful in therapy of dyslipidemia and hypertension, when a low-calorie diet alone is ineffective, and it confirm effectiveness of these nutraceuticals. Since low-fat diet alone for three months (before integration of monocolin $\mathrm{K}$ and glicomannan) did not achieve effects on metabolic parameters, the improvement in the lipid results could be attributed to a direct effect of monacolin $\mathrm{K}$ and glucomannan. In perspective, this experiment should be extended to younger subjects before appearance of metabolic syndrome. In this way, we could assess possible positive effects in prevention of metabolic syndrome.

\section{References}

1. Grundy SM, Brewer Jr HB, Cleeman Jl, Smith Jr SC, Lenfant C, American Heart Association, et al. (2004) Definition of metabolic syndrome: Report of the National Heart, Lung, and Blood Institute/American Heart Association conference on scientific issues related to definition. Circulation 109: 433-438.

2. Messina G, Dalia C, Tafuri D, Monda V, Palmieri F, et al. (2014) Orexin-A controls sympathetic activity and eating behavior. Front Psychol 5: 997.

3. Messina G, Vicidomini C, Viggiano A, Tafuri D, Cozza V, et al. (2012) Enhanced parasympathetic activity of sportive women is paradoxically associated to enhanced resting energy expenditure. Auton Neurosci Basic Clin 169: 102-106.

4. Monda M, Messina G, Vicidomini C, Viggiano A, Mangoni C, et al. (2006) Activity of autonomic nervous system is related to body weight in pre-menopausal, but not in post-menopausal women. Nutr Neurosci 9: 141-145.

5. Viggiano A, Vicidomini C, Monda M, Carleo D, Carleo R, et al. (2009) Fast and low-cost analysis of heart rate variability reveals vegetative alterations in noncomplicated diabetic patients. J Diabetes Complications 23: 119-123.

6. Messina G, Viggiano A, De Luca V, Messina A, Chieffi S, et al. (2013) Hormonal changes in menopause and orexin-a action. Obstet Gynecol Int 209812.

7. Messina G, De Luca V, Viggiano A, Ascione A, lannaccone T, et al. (2013) Autonomic nervous system in the control of energy balance and body weight: personal contributions. Neurol Res Int 1-5.

8. Viggiano A, Nicodemo U, Viggiano E, Messina G, Viggiano A, et al. (2010) Mastication overload causes an increase in $\mathrm{O} 2$ - production into the subnucleus oralis of the spinal trigeminal nucleus. Neuroscience 166: 416-421.

9. Monda M, Messina G, Mangoni C, De Luca B (2008) Resting energy expenditure and fat-free mass do not decline during aging in severely obese women. Clin Nutr 27: 657-659.

10. Monda M, Messina G, Scognamiglio I, Lombardi A, Martin GA, et al. (2014) Short-Term Diet and Moderate Exercise in Young Overweight Men Modulate Cardiocyte and Hepatocarcinoma Survival by Oxidative Stress. Oxid Med Cell Longev 1-7.

11. Di Bernardo G, Messina G, Capasso S, Del Gaudio S, Cipollaro M, et al. (2014) Sera of overweight people promote in vitro adipocyte differentiation of bone marrow stromal cells. Stem Cell Res Ther 5: 4

12. Esposito M, Serpe FP, Diletti G, Messina G, Scortichini G, et al. (2014) Serum levels of polychlorinated dibenzo-p-dioxins, polychlorinated dibenzofurans and polychlorinated biphenyls in a population living in the Naples area, southern Italy. Chemosphere 94: 62-69.

13. Viggiano A, Chieffi S, Tafuri D, Messina G, Monda M, De Luca B (2013) Laterality of a second player position affects lateral deviation of basketball shooting. J Sports Sci 37-41.

14. Chen $\mathrm{CH}$, Yang JC, Uang YS, Lin CJ. (2013) Improved dissolution rate and ora bioavailability of lovastatin in red yeast rice products. Int J Pharm 444: 18-24.

15. Venero CV, Venero JV, Wortham DC, Thompson PD. (2010) Lipid-lowering efficacy ofred yeast rice in a population intolerant to statins. Am J Cardiol 105: 664-666.

16. Furukawa S, Fujita T, Shimabukuro M, Iwaki M, Yamada Y, et al. (2004) Increased oxidative stress in obesity and its impact on metabolic syndrome. $J$ Clin Invest 114: 1752-1761. 
Citation: Esposito T, Allocca S, Adelfi L, Messina G, Monda M, et al. (2015) Effects of Monacolin K of Red Rice and Glucomannan, Combined with a Low Calorie Diet, in Treatment of Dyslipidemia and Hypertension. Biol Med (Aligarh) 7: 250. doi: 10.4172/0974-8369.1000250

Page 3 of 3

17. Keaney Jr JF, Larson MG, Vasan RS, Wilson PW, Lipinska I, et al. (2003) Obesity and systemic oxidative stress: clinical correlates of oxidative stress in the Framingham Study. Arterioscler Thromb Vasc Biol 23: 434-439.

18. Becker DJ, Gordon RY, Halbert SC, French B, Morris PB, et al. (2009) Red yeast rice for dyslipidemia in sttin- intolerant patients: randomized trial. Ann Intern Med 150: 830-839.

19. EFSA. Scientific Opinion on the substantiation of health claims related to monacolin $\mathrm{K}$ from red yeast rice and maintenance of normal blood LDL cholesterol concentrations (ID 1648, 1700) pursuant to Article 13(1) of Regulation (EC) No 1924/2006. EFSA J. 20119:2304

20. De Luca V, Viggiano E, Messina G, Viggiano A, Borlido C, et al. (2008) Peripheral amino acid levels in schizophrenia and antipsychotic treatment. Psychiatry Investig 5: 203-208.

21. Monda M, Amaro S, Sullo A, De Luca B (1995) Injection of muscimol in the posterior hypothalamus reduces the PGE1-hyperthermia in the rat. Brain Res Bull 37: 575-580.

22. Monda M, Viggiano A, Viggiano A, Viggiano E, Messina G, et al. (2007) Sympathetic and hyperthermic reactions by orexin A: Role of cerebral catecholaminergic neurons. Regul Pept 139: 39-44.

23. Monda M, Viggiano A, Viggiano A, Viggiano E, Messina G, et al. (2006) Quetiapine lowers sympathetic and hyperthermic reactions due to cerebral injection of orexin A. Neuropeptides 40: 357-363.

24. Menendez R, Arruzazabala ML, Mas R et al. (1997) Cholesterol-lowering effect of policosanol on rabbits with hupercolesterolemia induced by a starch-casein diet. $\mathrm{Br} J$ Nutr 77 : 923-32.
25. Arruzazabala ML, Carbajal D, Ms R, Del Río A, Amor AM, et al. (1994) Cholesterol-lowering effect of policosanol in rabbits. Biol Res 27: 205-208.

26. Heber D et al. (1999) Cholesterol-lowering effects of a proprietary Chinese redyeast-rice dietary. supplement. Am J Clin Nutr 69: 231-236.

27. Doi K (1990) Effect of Konjac fibre (glucomannan) on glucose and lipids. Eur J Clin Nutr 49: 190-197.

28. Blundell JE, Burley VJ (1987) Satiation, satiety and the action of fibre on food intake. Int J Obes11: 9-25.

29. Monda M, Viggiano A, Viggiano A, Fuccio F, De Luca V (2004) Injection of orexin a into the diagonal band of Broca induces symphatetic and hyperthermic reactions. Brain Res 1018: 265-271.

30. Monda M, Amaro S, Sullo A, De Luca B (1994) Posterior hypothalamic activity and cortical control during the PGE1 hyperthermia. Neuroreport 6: 135-139.

31. Monda M, Pittman QJ (1993) Cortical spreading depression blocks prostaglandin E1 and endotoxin fever in rats. Am J Physiol 264: R456-R459.

32. Esposito T, Uccello R, Caliendo R, Di Martino GF, Gironi Carnevale UA, et al. (2009) Estrogen receptor polymorphism, estrogen content and idiopathic scoliosis in human: a possible genetic linkage. J Steroid Biochem Mol Biol 116: $56-60$.

33. Esposito T, Varriale B, D'Angelo R, Amato A, Sidoti A (2014) Regulation of flavin-containing mono-oxygenase (Fmo3) gene expression by steroids in mice and humans. Horm Mol Biol Clin Investig 20: 99-109.

34. Esposito T, Napoleone A, Allocca S, Varriale B, Monda M (2014) Diet Therapy of Obesity: Observations on the Usefulness of Weekly Supervision in the Improvement of Weight Loss. J Obes Weight Loss Ther 4: 225. 